\title{
Penerapan Metode Logika Fuzzy dalam mengolah pilihan pada Game Visual Novel Informasi Penerimaan Mahasiswa Baru Fakultas Ilmu Komputer Universitas Muhammadiyah Riau sebagai Sarana Evaluasi Mandiri
}

\author{
M Djodi Andikarama ${ }^{1)}$, Yoze Rizki' ${ }^{2}$, Harun Mukhtar ${ }^{3)}$ \\ ${ }^{1}$ Teknik Informatika, Falkutas Ilmu Komputer, Universitas Muhammadiyah Riau \\ email:150401091@student.umri.ac.id \\ ${ }^{2}$ Teknik Informatika, Falkutas Ilmu Komputer, Universitas Muhammadiyah Riau \\ email: yozerizki@umri.ac.id \\ ${ }^{3}$ Teknik Informatika, Falkutas Ilmu Komputer, Universitas Muhammadiyah Riau \\ email: harunmukhtar@umri.ac.id
}

\begin{abstract}
Global developments are closely related to the progress of information technology and with the development of information, it is possible for the public to access information more easily, for example through android smartphone gadgets. Search for information on admission of new students by the University of Muhammadiyah Riau can be found through websites, brochures, telephone contacts, and social media. Along with the increasing quota provided for new students, admission information is needed to support the process of information dissemination, but until now the University of Muhammadiyah Riau itself does not yet have an android application-based information facility to support information dissemination to prospective new students. Seeing the problems that exist this study aims to build alternative means to help disseminate information to prospective new students. Therefore, the writer will build a media to help prospective new students to get information on New Student Admissions (PMB) through the special game media for Fasilkom UMRI. The game that will be used is Visual Novel type. Visual novel itself consists of pictures, sounds, and stories that can later help in the process of providing information. Another goal of this research is to design the Game storyline with Finite State Machine and implement the Fuzzy Logic method to process options in the Mini Game Evaluation and later this game will be built using Ren'Py with the Python programming language. This research is expected to help prospective new students of Fasilkom to obtain PMB information in an interesting, simple and interactive way..
\end{abstract}

Keywords: Game, Finite State Machine, Fuzzy, Visual Novel, Acceptance of New Students

\begin{abstract}
Abstrak
Perkembangan global erat kaitannya dengan kemajuan teknologi informasi dan dengan berkembangnya informasi memungkinkan masyarakat dapat mengakses informasi secara lebih mudah contohnya melalui gadget smartphone android. Pencarian informasi penerimaan mahasiswa baru oleh Universitas Muhammadiyah Riau dapat ditemukan melalui website, brosur, kontak telfon, dan social media. Seiring dengan bertambahnya kuota yang disediakan untuk mahasiswa baru, maka informasi penerimaan sangat diperlukan untuk menunjang proses penyebaran informasi akan tetapi sampai saat ini Universitas Muhammadiyah Riau sendiri belum memiliki sarana informasi berbasis aplikasi android untuk menunjang sosialisasi informasi kepada calon mahasiswa baru. Melihat permasalahan yang ada penelitian ini bertujuan untuk membangun sarana alternatif untuk membantu sosialisasi informasi kepada calon mahasiswa baru. Maka dari itu penulis akan membangun sebuah media untuk membantu calon mahasiswa baru agar bisa mendaptkan informasi Penerimaan Mahasiswa Baru (PMB) melalui media game khsususnya untuk Fasilkom UMRI. Game yang akan digunakan yaitu bertipe Visual Novel. Visual Novel sendiri terdiri dari gambar, suara, dan cerita yang nantinya dapat membantu dalam proses penyediaan informasi. Tujuan lain dari penelitian ini adalah untuk merancang alur cerita game dengan Finite State Machine serta mengimplementasi metode Logika Fuzzy untuk mengolah pilihan pada Mini Game Evaluasi dan nantinya game ini akan dibangun menggunakan Ren'Py dengan bahasa pemrograman Phyton. Dengan dibuatnya penelitian ini diharapkan dapat membantu calon mahasiswa baru Fasilkom untuk mendapatkan informasi PMB secara menarik, simpel, dan interaktif.
\end{abstract}

Kata Kunci: Game, Finite State Machine, Fuzzy, Visual Novel, Penerimaan Mahasiswa Baru

\section{Pendahuluan}

Perkembangan global erat kaitan-nya dengan kemajuan ilmu pengetahuan dan teknologi. Kehidupan masyarakat se-lalu mengikuti perkembangan tersebut. Masyarakat menggunakan berbagai macam teknologi yang dapat membantu kehidupannya sehari-hari. Gadget adalah salah satu fenomena yang sedang berkembang.Gadget bisa berupa smartphone, tablet, laptop, dan juga kamera.[1] Kemajuan teknologi komputer saat ini banyak mengalami perubahan yang besar. Sekarang manusia telah mampu mengembangkan aplikasi modern, salah satunya adalah komputer grafik. Perkembangan computer grafik saat ini, khususnya game dapat dikatakan sangat luar biasa. Ini merupakan salah satu dampak positif mengingat game merupakan media yang cukup lama bertahan.[12] 
Penerimaan mahasiswa baru disebuah universitas adalah momentum yang ditunggu oleh siapapun yang ingin menempuh ilmu dibangku perkuliahan khususnya calon-calon mahasiswa baru terutama di Universitas Muhammadiyah Riau yang dimana selalu membuka peluang kepada para calon mahasiswa baru untuk menempuh perkuliahan disana.

Universitas Muhammadiyah Riau adalah perguruan tinggi swasta dibawah kepemilikan Persyarikatan Muhammadiyah yang diselenggarakan oleh Pimpinan Wilayah Muhammadiyah Riau untuk melaksanakan pendidikan akademik dan professional dalam sejumlah disiplin ilmu, teknologi, seni, dan budaya. Tahun akademik 2019-2020, Universitas Muhammadiyah Riau berusaha meningkatkan kualitas mutu dengan melakukan penerimaan mahasiswa baru dengan system "One Day Service", yaitu : pelayanan satu hari. Maksudnya proses penerimaan mahasiswa baru dilaksanakan dalam satu hari, baik itu pendaftaran, tes masuk dan kelulusan.[20]

Berdasarkan buku panduan akademik Universitas Muhammadiyah Riau khususnya Fasilkom membuka 2 jalur penerimaan mahasiswa baru untuk periode tahun 2019/2020. Untuk mendapatkan informasi seputar jenis-jenis jalur penerimaan tersebut dapat diperoleh dari sarana seperti website UMRI, brosur, Contact Person UMRI, dan social media. Dengan hal - hal tersebut dapat dilihat bahwa Universitas Muhammadiyah Riau kurang efektif untuk melakukan perkembangan penyebaran informasi melalui smartphone karena dapat dilihat pada belum adanya sarana aplikasi smartphone android resmi milik Umri terkhususnya Fasilkom yang mana disaat universitas lainnya mengembangan info penerimaan mahasiswa baru melalui aplikasi pada smartphone Umri belum menerapkan hal tersebut ,terkhusus untuk Fasilkom yang seharusnya dapat memberikan hal baru pada umri dari sisi penerapan teknologi kedepannya salahsatunya dalam media penyebaran informasi. Padahal aplikasi Android saat ini sedang populer dan menjadi salah satu system aplikasi yang paling banyak digunakan di dunia saat ini.[7]

Dari permasalahan tersebut penulis ingin memberikan ide dalam meningkatkan keefektifan sosialisasi informasi mengenai PMB menggunakan aplikasi smartphone android bertipe game dalam menyampaikan dan mengenalkan informasi.

Dipilihnya sarana game pada penelitian ini karena hampir seluruh aplikasi PMB yang ada di Google Playstore menyajikannya dalam bentuk aplikasi media publikasi serupa dengan yang ada pada website, maka dengan aplikasi informasi bertipe game pengguna tidak hanya mendapatkan informasi mengenai PMB, tetapi juga mendapatkan cara baru yang menyangkan dalam memainkan game ditambah dengan adanya mini game yang akan menambah keseruan dan kepada pemain.

Bentuk ataupun tipe dari game yang akan penulis rancang adalah game bertipe visual novel yang nantinya didalam game ini akan tersaji panduan dalam memberikan informasi tentang PMB serta dengan ditambahnya minigame diharapkan bisa menjadikan game ini semakin menarik. Mekanika permainan nantinya akan sangat sederhana karena hanya terdiri dari membaca dan membuat keputusan dari beberapa pilihan, dimana pemain akan secara mandiri menentukan arah permainan dan juga aka nada mini game evaluasi mandiri yang akan menambah keseruan dan pengetahuan pemain saat memainkannya. Karena pada dasarnya sebuah Visual Novel dapat digunakan sebagai alternatif pembelajaran dari suatu hal, atau Visual Novel bisa menimbulkan minat untuk mengetahui sesuatu tema yang diangkat pada Visual Novel. [13]

Metode penelitian yang akan digunakan dalam game ini adalah dengan finite state machine dan logika fuzzy. Finite state machine sendiri dapat mendefinisikan prilaku kompleks menjadi kondisi yang dapat menjelaskan sebuah action sederhana. Selain itu penulis menggunakan logika fuzzy guna memberi nilai pada pilihan dalam mini game karena logika fuzzy mampu memberikan definisi terhadap sesuatu yang berada diantara nilai benar dan salah alias ambiguitas, setelah pilihan dalam mini game memiliki value maka nantinya value tersebut akan menghasilkan score point pada akhir game yang mana nantinya menunjukkan perolehan nilai serta output dari semua pilihan yang telah di pilih dan dari mini game ini para pemain bisa mengevaluasi kemampuannya dan minat prodi yang akan dipilih karena mini game ini sendiri akan menentukan seberapa jauh perminataannya untuk bergabung di prodi yang ada di fasilkom

Berdasarkan uraian diatas maka penulis akan melakukan penelitian dengan judul

"PENERAPAN METODE LOGIKA FUZZY DALAM MENGOLAH PILIHAN PADA GAME VISUAL NOVEL INFORMASI PENERIMAAN MAHASISWA BARU FASILKOM UMRI SEBAGAI SARANA EVALUASI MANDIRI" dan diharapkan dengan adanya penelitian ini penulis dapat membantu sosialisasi informasi penerimaan mahasiswa baru Fasilkom Umri dengan menarik, simpel, dan interaktif. 


\section{Metodologi Penelitian}

Pada bab ini menjelaskan tahapan tentang kerangka pemikiran, pengumpulan, analisis data, perancangan aplikasi, implementasi, pengujian, skripsi, jurnal. Yang mencakup kebutuhan fungsional dan kebutuhan non-fungsional yang pada akhirnya akan membantu dalam menyelsaikan tugas akhir.

\subsection{Kerangka Pemikiran}

Alur penelitian dilakukan untuk menguraikan rencana penelitian mulai dari pengumpulan dan analisis data sampai skripsi, jurnal, dengan tujuan agar materi yang disajikan dalam laporan skripsi sesuai dengan susunan dari alur penelitian yang sudah direncanakan. Berikut adalah langkahlangkah yang akan dilakukan dalam penelitian ini:

\begin{tabular}{|c|c|c|}
\hline \multicolumn{2}{|c|}{ Fase 1: Pengumpulan, Aanalisis Data \& Perancangan } \\
\hline $\begin{array}{c}\text { Observasi, } \\
\text { Pengumpulan } \\
\text { file multimedia, } \\
\text { studi literatur }\end{array}$ & $\begin{array}{c}\text { analisis kebutuhan } \\
\text { fungsional dan non } \\
\text { fungsional }\end{array}$ & $\begin{array}{l}\text { perancangan alur } \\
\text { cerita game dengan } \\
\text { FSM dan aplikasi } \\
\text { game VN PMB }\end{array}$ \\
FASILKOM UMRI
\end{tabular}

Gambar 2. 1 Kerangka Pemikiran

\subsection{Pengumpulan data}

\section{a. Observasi}

Dengan mengadakan peninjauan ke Universitas Riau bagian Fasilkom dan menanyakan langsung pada pihak Fasilkom dan menyetujui adanya pembuatan dan pengembangan game VN PMB FASILKOM UMRI untuk dijadikan alternatif informasi PMB Fasilkom UMRI.

\section{b. Studi Literatur}

Metode pengumpulan data dengan cara mengumpulkan literatur, dokumen, dan bacaanbacaan untuk mendapatkan gambaran tentang masalah yang diteliti.

\section{c. Pengumpulan file multimedia}

Proses selanjutnya adalah pengumpulan material multimedia yang dimana pada proses ini akan dilakukannya pengumpulan metierial yang dibutuhkan dalam pembuatan game seperti gambar tokoh, background, icon, dll. Berikut adalah beberapa komponen multimedia yang dipakai pada visual novel ini yaitu :

\section{Karakter Moderator}

Gambar karakter moderator meripakan gambar dari karakter yang akan membawakan penyajian materi, pengajuan pertanyaan serta akan mengolah pilihan dan respon yang dilakukan oleh $u$ ser.

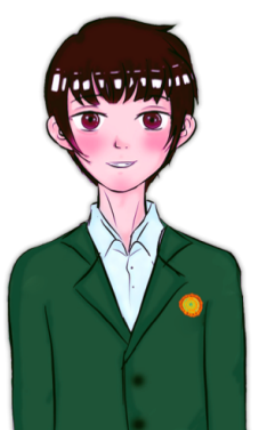

Gambar 2. 2 Karakter moderator

\section{Icon Game}

Gambar ini adalah icon yang akan tampil ketika aplikasi dibuka.

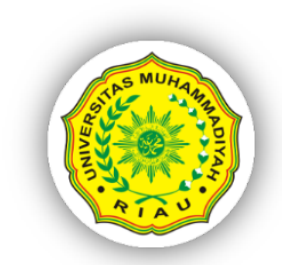

Gambar 2. 3 Icon Game

\section{Background}

Berikut adalah beberapa gambar background yang ada pada visual novel
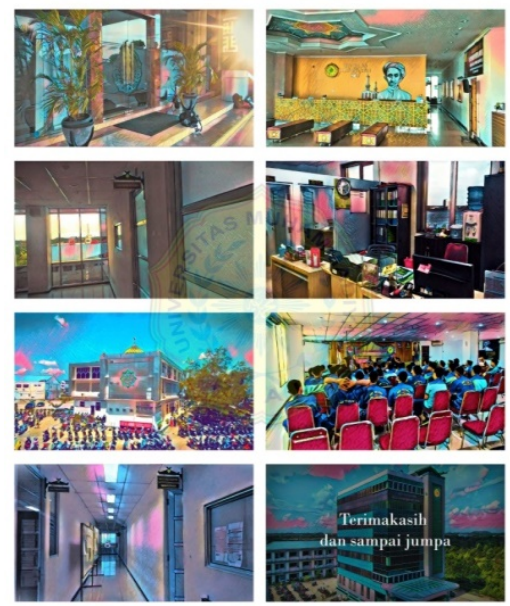

Gambar 2. 4 Background 


\subsection{Analisis}

\section{a. Analisis Kebutuhan Fungsional}

Spesifikasi kebutuhan fungsional yang ada pada penelitian ini dapat dilihat pada tabel 3.1 berikut:

Tabel 2. 1 Kebutuhan Fungsional

\begin{tabular}{|c|l|}
\hline No & \multicolumn{1}{|c|}{ Spesifikasi Kebutuhan Fungsional } \\
\hline 1 & $\begin{array}{l}\text { Game harus dapat menampilkan informasi } \\
\text { PMB alur online maupun alur offline }\end{array}$ \\
\hline 2. & $\begin{array}{l}\text { Game harus dapat menampilkan mini game } \\
\text { evaluasi }\end{array}$ \\
\hline 3 & $\begin{array}{l}\text { Game harus dapat menampilkan hasil akhir } \\
\text { dari mini game evaluasi }\end{array}$ \\
\hline
\end{tabular}

\section{b. Analisis Kebutuhan Non-Fungsional}

Analisis kebutuhan non-fungsional dilakukan untuk mengetahui spesifikasi kebutuhan yang akan dibangun. Spesifikasi kebutuhan melibatkan analisis perangkat keras dan analisis perangkat lunak.

\section{Perangkat keras (hardware)}

Perangkat keras yang akan digunakan memiliki spesifikasi sebagai berikut:

1. Processor Intel Celeron CPU (1.50 GHz)

2. Harddisk $300 \mathrm{~GB}$

3. RAM 4 GB DDR3

4. GPU Intel HD graphics $96 \mathrm{MB}$

\section{Perangkat Lunak (software)}

Perangkat lunak yang akan digunakan memiliki spesifikasi sebagai berikut:

1. Windows 10

2. Ren'py

3. Photoshop cc 2017

4. Ren'py Android Packaging Tool

\subsection{Perancangan aplikasi}

Perancangan aplikasi game VN PMB FASILKOM UMRI dimulai dengan menentukan alur cerita atau story line pada gamenya , karena konsep game visual novel pada dasarnya menciptakan game berdasarkan alur dan jalan cerita yang ada, maka dari itu game ini akan memiliki alur cerita yang di rancang menggunakan Finite State Machine agar cerita yang di hasilkan mampu berjalan sesuai konsep yang dimana dasar dari cerita pada game ini mengacu pada buku panduan FASILKOM UMRI

Perancangan kedua adalah mengumpulkan asset multimedia dan menyatukannya menjadi elemen pembentuk dalam pembuatan game $\mathrm{VN}$ PMB FASILKOM UMRI serta melakukan pengcodingan menggunakan aplikasi Ren'py.
Perancangan ketiga adalah membuat mini game evaluasi didalam game VN PMB FASILKOM UMRI yang dimana game ini akan memiliki gameplay soal yang berbasis pilihan ganda dan setiap pilihan atau jawaban yang dipilih akan mengeluarkan hasil apakah player memiliki kecenderungan pada prodi Teknik Informatika , Sistem Informasi , ataupun keduanya dan pada bagian ini akan diterapkan metode logika fuzzy untuk membantu mengolah pilihan pada mini game evaluasi ini.

\subsection{Implementasi}

Implementasi dilakukan menggunakan Ren'Py sebagai aplikasi atau engine untuk merancang game khusus visual novel dan dengan Phyton sebagai bahasa pemrogramannya, game ini bertema informasi alur cara pendaftaran serta juga menyajikan informasi singkat mengenai Fasilkom , Prodi Teknik Informatika dan juga Prodi Sistem Informasi. lalu pada akhir game visual novel ini akan ada mini game evaluasi untuk memprediksi pemain lebih cenderung kearah prodi Teknik Informatika , Sistem Informasi, ataupun keduanya (netral) . cara permainan mini game adalah dengan memilih pilihan yang disajikan dan tiap jawaban akan memiliki pengaruh yang mana nantinya akan membawa pemain untuk mendapatkan hasil evaluasi mandiri berdasarkan pilihan yang pemain pilih. Serta dalam pengembangannya soal pilihan ini akan menerapkan metode logika fuzzy untuk mengolah pilihan agar pemain bisa mendapatkan output evaluasi yang sesuai dari pilihan yang sudah di pilih oleh pemain yang dimana pilihan akan memiliki 4 opsi jawaban tiap 1 soal yang diberikan dan di dalam mini game ini terdapat 5 soal pilihan, lalu didalam tiap pilihan jawban di dalam soal memiliki bobot dan kelas yang berbeda dimana ada kelas TI dan kelas SI didalamnya,

\subsection{Pengujian}

Dalam pengujian tahap ini akan dilakukan dengan memakai contoh kasus yang dimana contoh kasus ini akan mengeluarkan output dari tiap jawaban yang dipilih pada mini game, setelah nilai output keluar maka akan dilakukan proses inferensi dan defuzzifikasi untuk mengubah data output tiap pilihan menjadi data tegas atau crisp yang mana crisp ini berisi kecocokan terhadap Teknik Informatika, Sistem Informasi, ataupun keduanya.

Dalam pengujian tahap selanjutnya berupa pengujian software yang dilakukan untuk mendapatkan informasi mengenai kualitas dari produk atau layanan yang sedang di uji atau diteliti serta dengan adanya pengujian ini dapat memberikan pandangan mengenai software secara 
objektif dan independen agar bisa memahami tingkat resiko pada implementasinya.

\section{Hasil dan Pembahasan}

Pada bab ini menjelaskan tentang pengumpulan dataset, analisis, Implementasi FSM, assembly game, Implementasi Logika Fuzzy, pengujian dengan contoh kasus, hasil pengujian, kesimpulan dan saran yang nantinya akan membantu dalam menyelesaikan tugas akhir.

Berikut tampilan flowchart system pada game VN PMB FASILKOM UMRI dapat dilihat pada Gambar 4.1

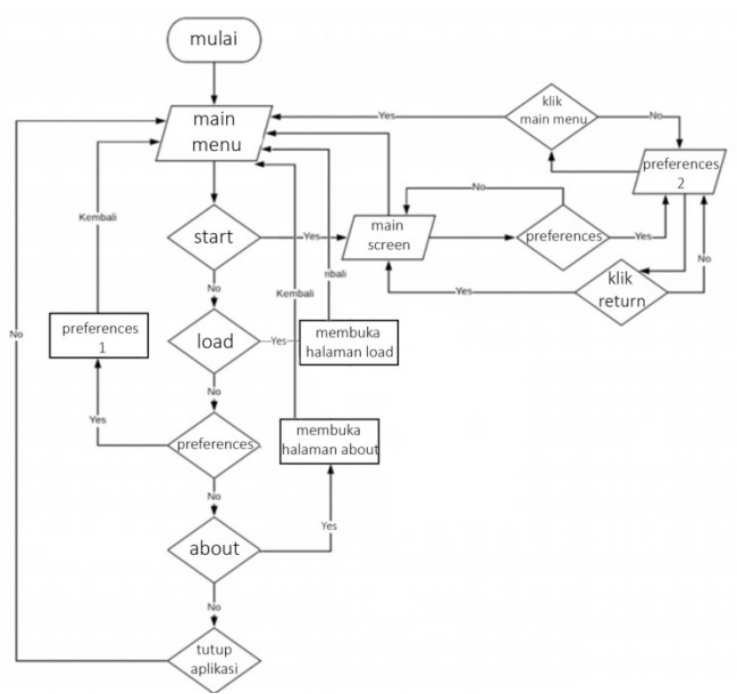

Gambar 3. 1 Flowchart Sistem

\subsection{Implementasi FSM pada Story Line}

Pada Game ini akan dirancang penggunaan FSM pada alur ceritanya dan di jelaskan dengan state diagram, dalam diagram ini menjelaskan tentang alur cerita utama game. Pemain memilih keputusan terkait pilihan yang ada, bahkan pilihan sudah di bentuk di awal game dalam bentuk pilihan siap bermain atau belum siap bermain, disini setiap informasi yang tersedia hanya dapt diakses dengan cara memilih 1 dari pilihan yang tidak berulang atau diakses kembali selain memilih tombol back, berikut state diagram FSM:

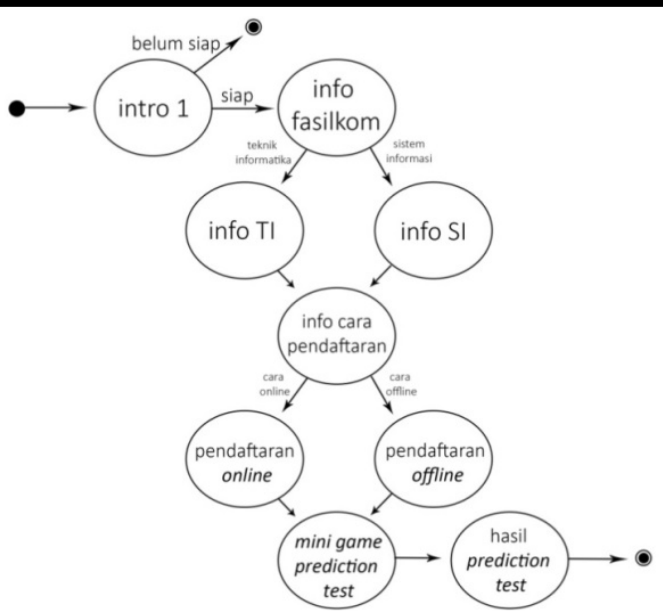

Gambar 3. 2 State Diagram FSM

Pada Gambar 3.2 diatas memperlihatkan statestate dari posisi pemain dalam game:

a. Intro 1 : state intro 1 berisi intro dari karakter moderator kepada pemain pada state ini moderator memperkenalkan diri dan memperkenalkan tugasnya sembari bertanya kepada pemain apakah sudah siap untuk bermain atau belum

b. Info Fasilkom : state info fasilkom berisi tentang info singkat tentang fasilkom dan state ini didapatkan setelah memilih pilihan siap

c. Info TI : state yang didapatkan setelah pemain memilih pilihan Teknik Informatika

d. Info SI : state yang didapatkan setelah pemain memilih pilihan Sistem Informasi

e. info cara pendaftaran : state yang akan keluar setelah pemain memilih pilihan Info SI ataupun Info TI

f. Pendaftaran Online : state yang akan keluar saat pemain memilih pilihan cara online setelah state info cara pendaftaran

h. Pendaftaran Offline : state yang akan keluar saat pemain memilih pilihan cara offline setelah state info cara pendaftaran

i. mini game evaluation test: state intro soal evaluasi yang diperoleh setelah pemain memilih state Pendaftaran Online ataupun Pendaftaran Offline

j. Hasil prediction test : state hasil daripada mini game yang tadi dijalankan serta mengeluarkan hasil output berupa kesimpulan dari pilihan soal

Pemain dapat memilih siap ataupun belum siap pada pilihan awal, jika memilih siap maka akan dilanjut kepada state info fasilkom akan tetapi jika memilih belum siap maka pemain akan diarahkan kepada main menu awal, setelah memilih siap dan mendapat state info fasilkom dan mendapat informasi fasilkom maka pemain dihadapkan lalgi dengan 2 pilihan antara Info TI ataupun Info SI setiap pilihan yang dipilih akan mendapatkan hasil outpun berbeda tergantung dari pilihan yang dipilih, jika memilih TI maka akan mendapatkan 
informasi TI begitu pula memilih info SI akan mendapatkan info SI.

Setelah pemain memilih pilihan info TI ataupun SI maka pemain akan disuguhkan kedalam intro cara pendaftaran disana akan dijelaskan secara singkat mengenai adanya 2 cara pendaftaran, setelah dari state cara pendaftaran maka pemain akan diberikan pilihan lagi yaitu memilih cara offline untuk mendapatkan info pendaftaran offline dan memilih info online untuk mendapatkan info pendaftaran online, setelah dari info pendaftaran online maupun offline maka pemain akan diarahkan ke intro mini game evaluation test dan pada state ini pemain bisa memilih ingin memainkan mini game, setelah dari minigame maka pemain akan mencapai state yang mana pada state ini pemain bisa melihat kesimpulan dari pilihan yang telah pemain pilih dalam melakukan mini game evaluation test.

\subsection{Implementasi Logika Fuzzy}

Pada visual novel PMB FASILKOM UMRI ini, logika fuzzy akan diterapkan melalui 3 tahapan yaitu :

1. Fuzzifikasi

2. Inference Engine atau Mesin Penalaran

\section{Defuzzifikasi}

\subsubsection{Fuzzifikasi}

Proses fuzzifikasi dipergunakan untuk mengubah data masukkan tegas (crisp) kedalam bentuk himpunan keanggotaan. Pada visual novel PMB FASILKOM UMRI ini, fuzzifikasi akan dilakukan terhadap opsi pilihan yang ada pada visual novel.

Akan ada 5 soal yang diimplementasikan fuzzy pada visual novel edukasi jaringan ini yang masing-masing pertanyaan atau soal tersebut akan memiliki 4 opsi pilihan. Pada setiap opsi pilihan yang diterapkan fuzzy akan memiliki value yang berkisar dari 10 sampai 20. Setiap opsi pilihan yang ada juga akan memiliki respon berbeda. Dan pada pilihan disini terdapat soal pilihan TI dan juga SI maka dari itu berikut soal yang telah di ambil berdasarkan buku panduan dan dikumpulkan melalui teknik simple random sampling.

Tabel 3. 1 Data Jawaban yang akan dijadikan pilihan pada soal

\begin{tabular}{|l|c|c|c|}
\hline $\begin{array}{l}\text { N } \\
\text { o }\end{array}$ & Soal pilihan TI & Soal pilihan SI & $\begin{array}{c}\text { Tingk } \\
\text { atan } \\
\text { Soal }\end{array}$ \\
\hline
\end{tabular}

\begin{tabular}{|c|c|c|c|}
\hline 1 & $\begin{array}{l}\text { Kemampuan } \\
\text { melakukan } \\
\text { penanganan } \\
\text { pada barang } \\
\text { bukti digital }\end{array}$ & $\begin{array}{l}\text { Kemampuan } \\
\text { menjelaskan } \\
\text { konsep dan teori } \\
\text { dasar logika dan } \\
\text { struktur diskrit } \\
\text { untuk mendukung } \\
\text { permodelan dan } \\
\text { penganalisaan } \\
\text { masalah }\end{array}$ & Khusus \\
\hline 2 & $\begin{array}{l}\text { Kemampuan } \\
\text { menganalisa dan } \\
\text { merancang } \\
\text { bangun aplikasi } \\
\text { berbasis android } \\
\text { dengan } \\
\text { menggunakan } \\
\text { Android Studio }\end{array}$ & $\begin{array}{l}\text { Kemampuan } \\
\text { menjelaskan } \\
\text { prinsip-prinsip } \\
\text { dasar dari } \\
\text { integritas, } \\
\text { keamanan dan } \\
\text { tingkat } \\
\text { kerahasiaan data } \\
\text { pada suatu basis } \\
\text { data }\end{array}$ & Khusus \\
\hline 3 & $\begin{array}{l}\text { Kemampuan } \\
\text { menganalisa } \\
\text { kebutuhan akan } \\
\text { pembuatan game } \\
\text { yang sesuai } \\
\text { dengan } \\
\text { kebutuhan }\end{array}$ & $\begin{array}{l}\text { Kemampuan } \\
\text { menjelaskan } \\
\text { aspek-aspek } \\
\text { quality assurance } \\
\text { pada suatu } \\
\text { pengelolaan } \\
\text { proyek sistem } \\
\text { informasi }\end{array}$ & Khusus \\
\hline 4 & $\begin{array}{l}\text { Kemampuan } \\
\text { penguasaan } \\
\text { manajemen } \\
\text { jaringan } \\
\text { komputer }\end{array}$ & $\begin{array}{l}\text { Kemampuan } \\
\text { menjelaskan } \\
\text { berbagai teknik } \\
\text { dan metode } \\
\text { pengambilan } \\
\text { keputusan dalam } \\
\text { pemecahan } \\
\text { masalah } \\
\text { organisasi }\end{array}$ & Khusus \\
\hline 5 & $\begin{array}{l}\text { Kemampuan } \\
\text { menerapkan } \\
\text { keterampilan } \\
\text { kognitif khusus } \\
\text { dan pengetahuan } \\
\text { tentang dunia } \\
\text { nyata pada } \\
\text { masalah yang } \\
\text { tidak jelas serta } \\
\text { dapat } \\
\text { mengembangkan } \\
\text { desain AR yang } \\
\text { tepat }\end{array}$ & $\begin{array}{l}\text { Kemampuan } \\
\text { membangun dan } \\
\text { mengembangkan } \\
\text { bisnis dibidang } \\
\text { sistem informasi }\end{array}$ & Khusus \\
\hline
\end{tabular}




\begin{tabular}{|c|c|c|c|}
\hline 6 & $\begin{array}{l}\text { Kemampuan } \\
\text { penguasaan } \\
\text { konsep dan ilmu } \\
\text { probabilitas dan } \\
\text { statistik untuk } \\
\text { mendukung dan } \\
\text { menganalisis } \\
\text { sistem } \\
\text { komputasi }\end{array}$ & $\begin{array}{l}\text { Kemampuan } \\
\text { melakukan } \\
\text { dakwah sesuai } \\
\text { bidang ilmunya } \\
\text { dalam bingkai AL } \\
\text { Islam dan } \\
\text { Kemuhammadiya } \\
\text { han }\end{array}$ & Umum \\
\hline 7 & $\begin{array}{l}\text { Kemampuan } \\
\text { penguasaan } \\
\text { sistim } \\
\text { permodelan } \\
\text { matematika, } \\
\text { program linear } \\
\text { serta metode } \\
\text { numerik }\end{array}$ & $\begin{array}{l}\text { Kemampuan } \\
\text { mengambil } \\
\text { keputussan secara } \\
\text { tepat dengan } \\
\text { konteks } \\
\text { penyelesaian } \\
\text { masalah di bidang } \\
\text { keahliannya, } \\
\text { berdasarkan hasil } \\
\text { analisis informasi } \\
\text { dan data }\end{array}$ & Umum \\
\hline 8 & $\begin{array}{l}\text { Kemampuan } \\
\text { membangun } \\
\text { aplikasi } \\
\text { perangkat lunak } \\
\text { yang berkaitan } \\
\text { dengan } \\
\text { pengetahuan } \\
\text { ilmu komputer }\end{array}$ & $\begin{array}{l}\text { Kemampuan } \\
\text { mendokumentasik } \\
\text { an, menyimpan, } \\
\text { mengamankan, } \\
\text { dan menemukan } \\
\text { kembali data } \\
\text { untuk menjamin } \\
\text { kesahihan dan } \\
\text { mencegah plagiasi }\end{array}$ & Umum \\
\hline 9 & $\begin{array}{l}\text { Kemampuan } \\
\text { integritas } \\
\text { profesional dan } \\
\text { berkomitmen } \\
\text { terhadap nilai- } \\
\text { nilai etika }\end{array}$ & $\begin{array}{l}\text { Kemampuan } \\
\text { menunjukan } \\
\text { kinerja mandiri, } \\
\text { bermutu, dan } \\
\text { terukur }\end{array}$ & Umum \\
\hline $\begin{array}{l}1 \\
0\end{array}$ & $\begin{array}{l}\text { Kemampuan } \\
\text { melakukan } \\
\text { rancang bangun } \\
\text { perangkat keras } \\
\text { dan lunak } \\
\text { (embedded } \\
\text { system) dengan } \\
\text { menggunakan } \\
\text { metode, teknik } \\
\text { dan alat bantu } \\
\text { sesuai kebutuhan } \\
\text { pengguna }\end{array}$ & \begin{tabular}{lr}
\multicolumn{2}{l}{ Kemampuan } \\
berkomunikasi \\
lisan dan & tulisan \\
dalam & bahasa \\
indonesia & dan \\
bahasa inggris & dengan baik
\end{tabular} & Umum \\
\hline
\end{tabular}

Dan berikut hasil fuzzifikasi soal yang akan di berikan berdasarkan data jawaban yang telah didapatkan diatas yang memiliki value berkisar 10 hingga 20 :

\subsection{Scene Pilihan 1}

Tabel 3. 2 Fuzzifikasi Soal Pertama

\begin{tabular}{|c|c|c|}
\hline Opsi & Value & Respon \\
\hline $\begin{array}{l}\text { 1."Kemampuan melakukan } \\
\text { penanganan pada barang bukti } \\
\text { digital" }\end{array}$ & $20 \mathrm{TI}$ & Senang \\
\hline $\begin{array}{l}\text { 2."Kemampuan penguasaan } \\
\text { konsep dan ilmu probabilita dan } \\
\text { statistik untuk mendukung dan } \\
\text { menganalisis sistem komputasi" }\end{array}$ & $10 \mathrm{TI}$ & Senyum \\
\hline $\begin{array}{l}\text { 3. "Kemampuan menjelaskan } \\
\text { konsep dan teori dasar logika } \\
\text { dan struktur diskrit untuk } \\
\text { mendukung permodelan dan } \\
\text { penganalisaan masalah" }\end{array}$ & $20 \mathrm{SI}$ & Senang \\
\hline $\begin{array}{l}\text { 4." Kemampuan melakukan } \\
\text { dakwah sesuai bidang ilmunya } \\
\text { dalam bingkai AL Islam dan } \\
\text { Kemuhammadiyahan" }\end{array}$ & $10 \mathrm{SI}$ & Senyum \\
\hline
\end{tabular}

\subsection{Scene pilihan 2}

Tabel 3. 3 Fuzzifikasi Soal kedua

\begin{tabular}{|c|c|c|}
\hline Opsi & Value & Respon \\
\hline $\begin{array}{l}\text { 1."Kemampuan menganalisa dan } \\
\text { merancang bangun aplikasi } \\
\text { berbasis android dengan } \\
\text { menggunakan Android Studio" }\end{array}$ & $20 \mathrm{TI}$ & Senang \\
\hline $\begin{array}{l}\text { 2. "Kemampuan penguasaan } \\
\text { sistim permodelan matematika, } \\
\text { program linear serta metode } \\
\text { numerik" }\end{array}$ & $10 \mathrm{TI}$ & Senyum \\
\hline $\begin{array}{l}\text { 3. "Kemampuan } \\
\text { menjelaskan } \\
\text { prinsip-prinsip dasar dari } \\
\text { integritas, keamanan dan tingkat } \\
\text { kerahasiaan data pada suatu } \\
\text { basis data" }\end{array}$ & $20 \mathrm{SI}$ & Senang \\
\hline $\begin{array}{l}\text { 4. "Kemampuan mengambil } \\
\text { keputussan secara tepat dengan } \\
\text { konteks penyelesaian masalah di } \\
\text { bidang keahliannya, berdasarkan } \\
\text { hasil analisis informasi dan data" }\end{array}$ & $10 \mathrm{SI}$ & Senyum \\
\hline
\end{tabular}

\subsection{Scene pilihan 3}

Tabel 3. 4 Fuzzifikasi Soal ketiga

\begin{tabular}{|l|l|l|}
\hline \multicolumn{1}{|c|}{ Opsi } & Value & Respon \\
\hline $\begin{array}{l}\text { 1."Kemampuan menganalisa } \\
\text { kebutuhan akan pembuatan game } \\
\text { yang sesuai dengan kebutuhan" }\end{array}$ & $20 \mathrm{TI}$ & Senang \\
\hline $\begin{array}{l}\text { 2."Kemampuan membangun aplikasi } \\
\text { perangkat lunak yang berkaitan } \\
\text { dengan pengetahuan ilmu komputer" }\end{array}$ & & \\
\hline
\end{tabular}




\begin{tabular}{|l|l|l|}
\hline $\begin{array}{l}\text { 3."Kemampuan menjelaskan aspek- } \\
\text { aspek quality assurance pada suatu } \\
\text { pengelolaan proyek sistem } \\
\text { informasi" }\end{array}$ & Senang \\
\hline $\begin{array}{l}\text { 4."Kemampuan mendokumentasikan, } \\
\text { menyimpan, mengamankan, dan } \\
\text { menemukan kembalidata untuk } \\
\text { menjamin kesahihan dan mencegah } \\
\text { plagiasi" }\end{array}$ & & \\
\hline
\end{tabular}

\subsection{Scene pilihan 4}

Tabel 3. 5 Fuzzifikasi Soal keempat

\begin{tabular}{|l|c|c|}
\hline \multicolumn{2}{|c|}{ Opsi Value } & Respon \\
\hline $\begin{array}{l}\text { 1."Kemampuan penguasaan } \\
\text { manajemen jaringan komputer" }\end{array}$ & $20 \mathrm{TI}$ & Senang \\
\hline $\begin{array}{l}\text { 2."Kemampuan integritas } \\
\text { profesional dan berkomitmen } \\
\text { terhadap nilai-nilai etika" }\end{array}$ & $10 \mathrm{TI}$ & Senyum \\
\hline $\begin{array}{l}\text { 3."Kemampuan menjelaskan } \\
\text { berbagai teknik dan metode } \\
\text { pengambilan keputusan dalam } \\
\text { pemecahan masalah organisasi" }\end{array}$ & & \\
\hline $\begin{array}{l}\text { 4. "Kemampuan menunjukan } \\
\text { kinerja mandiri, bermutu, dan } \\
\text { terukur" }\end{array}$ & $10 \mathrm{SI}$ & Senyum \\
\hline
\end{tabular}

\subsection{Scene pilihan TI 5}

Tabel 3. 6 Fuzzifikasi Soal kelima

\begin{tabular}{|c|c|c|}
\hline Opsi & Value & Respon \\
\hline $\begin{array}{l}\text { 1."Kemampuan menerapkan } \\
\text { keterampilan kognitif khusus } \\
\text { dan pengetahuan tentang dunia } \\
\text { nyata pada masalah yang tidak } \\
\text { jelas serta dapat } \\
\text { mengembangkan desain AR } \\
\text { yang tepat" }\end{array}$ & $20 \mathrm{TI}$ & Senang \\
\hline $\begin{array}{l}\text { 2."Kemampuan melakukan } \\
\text { rancang bangun perangkat keras } \\
\text { dan lunak (embedded system) } \\
\text { dengan menggunakan metode, } \\
\text { teknik dan alat bantu sesuai } \\
\text { kebutuhan pengguna" }\end{array}$ & $10 \mathrm{TI}$ & Senyum \\
\hline $\begin{array}{l}\text { 3."Kemampuan membangun } \\
\text { dan mengembangkan bisnis } \\
\text { dibidang sistem informasi" }\end{array}$ & $20 \mathrm{SI}$ & Senang \\
\hline $\begin{array}{l}\text { 4."kemampuan berkomunikasi } \\
\text { lisan dan tulisan dalam bahasa } \\
\text { indonesia dan bahasa inggris } \\
\text { dengan baik" }\end{array}$ & $10 \mathrm{SI}$ & Senyum \\
\hline
\end{tabular}

\subsubsection{Inference Engine atau Mesin Penalaran}

Inference engine atau mesin penalaran merupakan langkah kedua dalam pemrosesan logika fuzzy. Inference engine atau mesin penalaran digunakan untuk mengkombinasi aturan-aturan JIKA-MAKA (IFTHEN) yang terdapat dalam setiap basis aturan kedalam suatu pemetaan dari suatu himpunan fuzzy input kesuatu himpunan fuzzy output. Input maupun output dari inference engine atau mesin penalaran adalah crisp value.

Contoh Kasus :

User bernama jodi bermain visual novel PMB FASILKOM UMRI jodi berhasil mengumpulkan value sebesar 50 TI dan 30 SI Value tersebut didapat dari :

1. Pada scene pertama, jodi memilih "Kemampuan melakukan penanganan pada barang bukti digital", sehingga mendapat value sebesar $20 \mathrm{TI}$

2. Pada scene kedua, jodi memilih "Kemampuan penguasaan sistim permodelan matematika, program linear serta metode numerik" sehingga mendapat value sebesar $10 \mathrm{TI}$

3. Pada scene ketiga, jodi memilih "Kemampuan menjelaskan aspek-aspek quality assurance pada suatu pengelolaan proyek sistem informasi", sehingga mendapat value sebesar $20 \mathrm{SI}$

4. Pada scene keempat,jodi memilih "Kemampuan penguasaan manajemen jaringan komputer"sehingga mendapat value sebesar $20 \mathrm{TI}$

5. Pada scene kelima, jodi memilih "kemampuan berkomunikasi lisan dan tulisan dalam bahasa indonesia dan bahasa inggris dengan baik" sehingga mendapat value sebesar $10 \mathrm{SI}$

Dalam pemetaan output fuzzy yang berupa penilaian mandiri terhadap user jodi pada visual novel ini, digunakanlah representasi linear dengan metode additive (sum) yang dimana solusi himpunan fuzzy yang diperoleh menggunakan dengan melakukan bounded sum terhadap semua output fuzzy pada soal maka setelah dijumlahkan didaptakanlah value terakhir $50 \mathrm{TI}$ dan $30 \mathrm{SI}$ lalu di petakan dalam representasi linear sebagai berikut : 

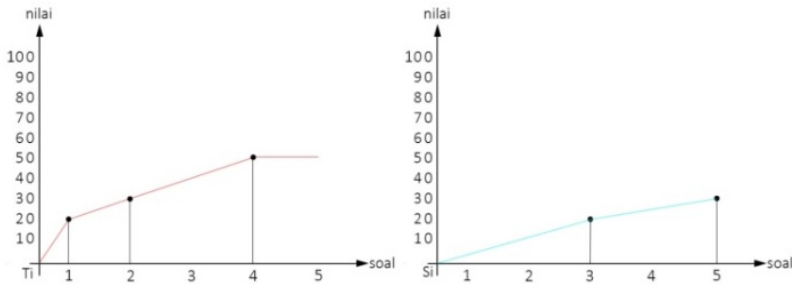

Gambar 3. 3 Representasi Linear

Penjelasan berikut meliputi nilai TI dan SI yang dimana nilai TI didapatkan dari masukan pilihan yang terlah diambil sebelumnya yaitu pilihan 1 menjawab $20 \mathrm{TI}$, pilihan 2 menjawab 10 TI , dan pilihan 3 menjawab 20 TI dan dilakukan bounded hingga menghasilkan hasil akhir 50 TI, sedangkan nilai SI didapatkan dari masukan pilihan 3 menjawab 20 SI dan pilihan 5 menjawab 10 SI dan dilakukan bounded hinhha menghasilkan hasil akhir 30 SI.

\subsubsection{Defuzzifikasi}

Defuzzifikasi merupakan proses pemetaan himpunan fuzzy menjadi tegas (crisp). Proses ini merupakan kebalikan dari proses fuzzifikasi. Input dari proses defuzzifikasi adalah suatu himpunan fuzzy yang diperoleh dari keseluruhan komposisi fuzzy, sedangkan output yang dihasilkan merupakan suatu bilangan pada domain himpunan fuzzy tersebut, sehingga jika diberikan suatu himpunan fuzzy dalam range tertentu, maka harus dapat diambil suatu nilai crisp tertentu sebagai keluarannya.

Defuzzifikasi pada metode ini,menggunakan metode penyelesaian LOM (Largest of Maximum) yang dimana penyelesaian crisp diperoleh dengan cara mengambil nilai rata-rata domain fuzzy yang memiliki nilai maksimum dari inference engine sebelumnya yang mana solusi himpunan fuzzy yang diperoleh dengan cara melakukan bounded sum terhadap semua output fuzzy yang ada. Setelah melakukan bounded sum, maka value terakhir akan didapatkan. Value terakhir tersebut akan menentukan nilai tegas atau crisp sebagai outputnya. Berikut adalah tabel deffuzifikasi pada prediction test :

Tabel 3. 7 Himpunan Defuzzifikasi Visual

\begin{tabular}{|c|c|}
\hline \multicolumn{2}{|c}{ Novel } \\
\hline Nilai Tegas (Crisp) & Range Value \\
\hline Cenderung TI & TI $>$ SI dan SI $<$ TI \\
\hline Cenderung SI & SI $>$ TI dan TI $<$ SI \\
\hline TI dan juga SI & TI $==$ SI \\
\hline
\end{tabular}

Jika menggunakan contoh kasus user jodi yang dimana user jodi berhasil mengumpulkan value akhir sebesar 50 TI dan 30 SI pada soal evaluasi, maka nilai tegas (crisp) yang akan didapatkan sebagai output defuzzifikasi adalah "CENDERUNG TI" dikarenakan value nilai TI lebih besar dari SI dan nilai SI lebih kecil dari nilai TI. Tampilan defuzzifikasi user Jodi pada visual novel dapat dilihat pada gambar berikut :

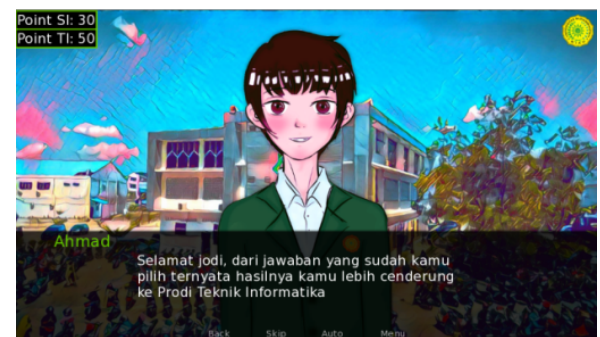

Gambar 3. 4 Defuzzifikasi pada Visual Novel

Defuzzifikasi pada visual novel ini berguna untuk memberikan evaluasi akhir yang berbentuk penilaian mandiri terhadap user yang memainkan visual novel ini sampai selesai.

\subsection{Hasil Pengujian Sistem}

Berikut ini adalah tampilan dari visual novel $\mathrm{PMB}$ FASILKOM UMRI:

1. Tampilan Menu Utama

Ketika visual novel ini dibuka pada maka tampilan awal dari program seperti, gambar dibawah ini :

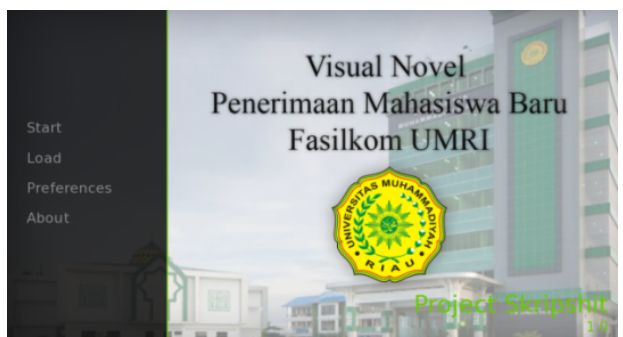

Gambar 3. 5 Tampilan Menu Utama
2. Tampilan Saat Narasi

Tampilan merupakan tampilan yang akan muncul pada saat narasi di visual novel sedang berlangsung. 


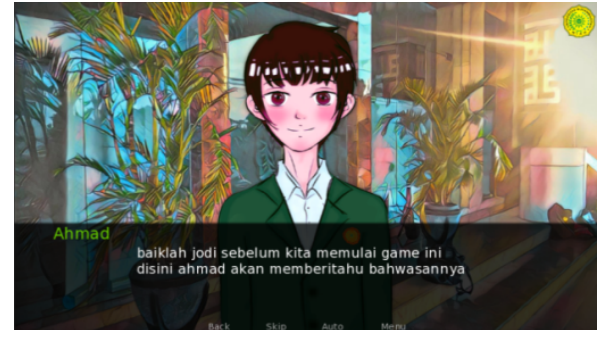

Gambar 3. 6 Tampilan Saat Narasi

3. Tampilan "History"

Tampilan ini akan menampilkan menampilkan narasi apa saja yang sudah dilewati mulai dari awal sampai narasi terakhir.

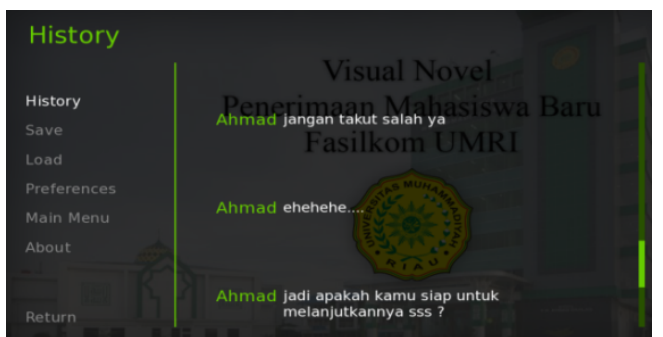

Gambar 3. 7 Tampilan "History"

4. Tampilan "Save"

Ini adalah tampilan dari save yang apabila user ingin menyimpan progress mereka.

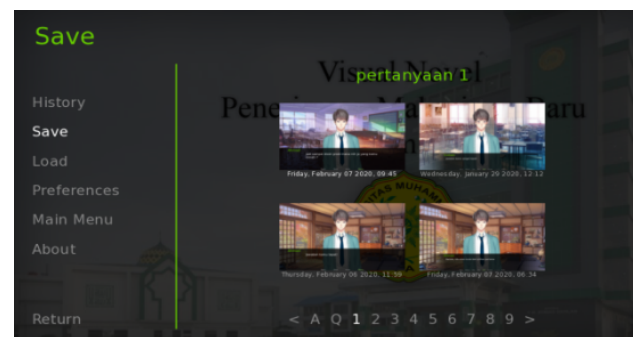

Gambar 3.8 Tampilan "Save"

5. Tampilan "Prefs"

Ini adalah tampilan prefs dimana user bisa melakukan adjusting terhadap setting pada visual novel.

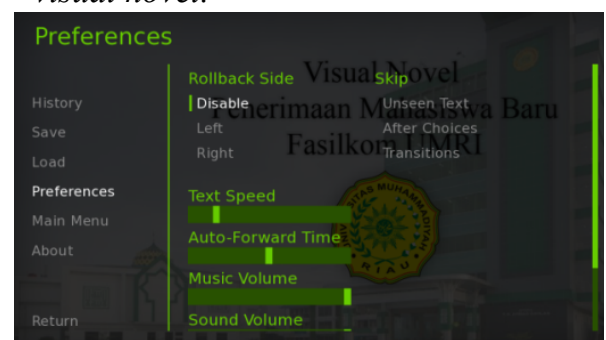

Gambar 3.9 Tampilan "Prefs"

6. Tampilan Saat Memilih

Ini adalah tampilan saat user akan memilih pilihan yang ada pada visual novel

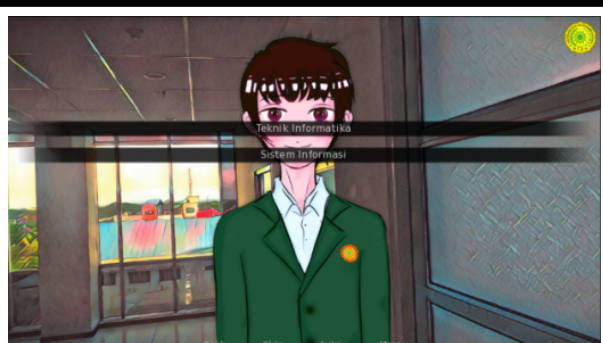

Gambar 3. 10 Tampilan Saat Memilih

7. Tampilan "Load"

Tampilan ini akan muncul apabila user ingin melakukan load pada save file yang pernah disimpan.

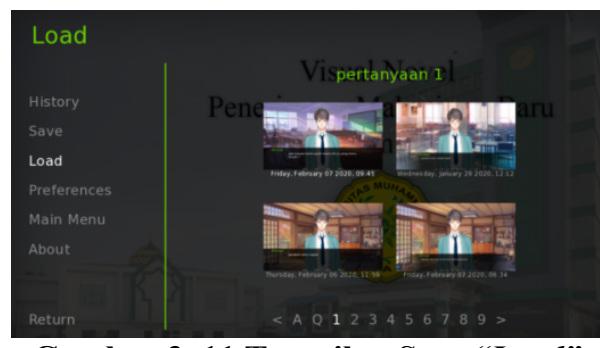

Gambar 3. 11 Tampilan Saat "Load"

8. Tampilan "About"

Tampilan ini berisi informasi mengenai aplikasi visual novel dan ren'py yang digunakan dalam pembuatannya.

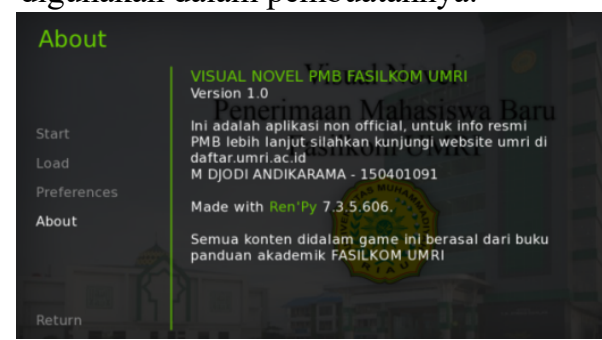

Gambar 3. 12 Tampilan “About"

9. Tampilan Informasi FASILKOM

Tampilan ini berisi informasi mengenai informasi singkat tentang Fasilkom

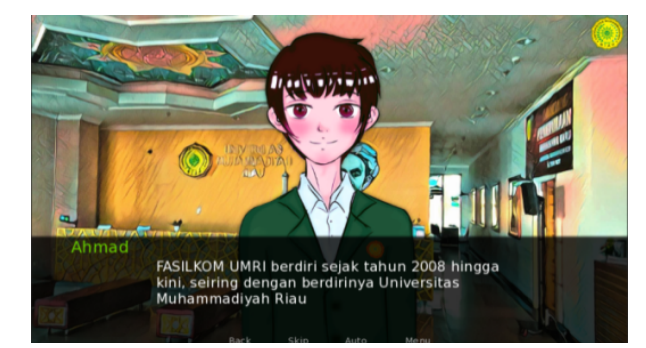

Gambar 3. 13 Tampilan "info FASILKOM"

10. Tampilan Informasi "informasi singkat TI" Tampilan ini berisi informasi mengenai informasi singkat Teknik Informatika. 


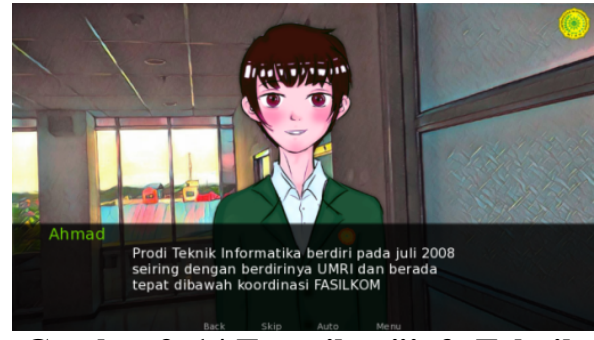

Gambar 3. 14 Tampilan "info Teknik Informatika"

11. Tampilan Informasi "informasi singkat SI" Tampilan ini berisi informasi mengenai informasi singkat Sistem Informasi.

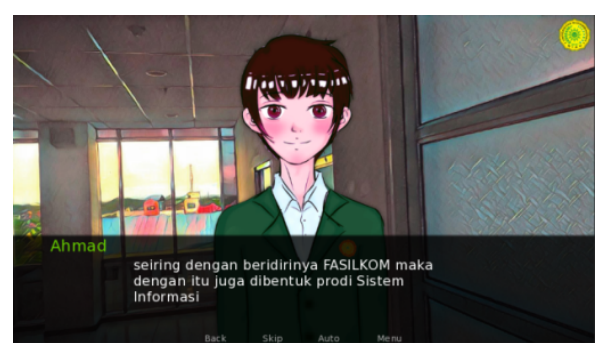

\section{Gambar 3. 15 Tampilan "info Sistem} Informasi"

12. Tampilan Informasi "alur online" Tampilan ini berisi informasi mengenai informasi alur pendaftaran secara online.

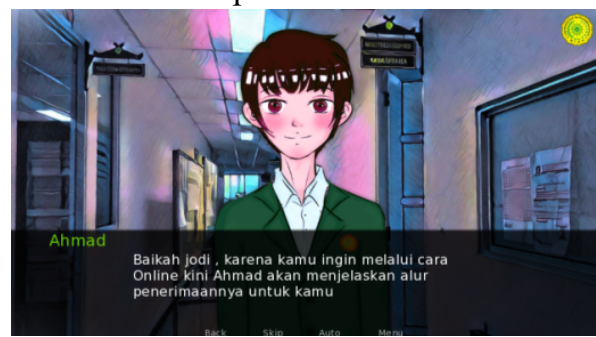

Gambar 3. 16 Tampilan informasi "alur online"

13. Tampilan Informasi "alur offline"

Tampilan ini berisi informasi mengenai informasi alur pendaftaran secara offline.

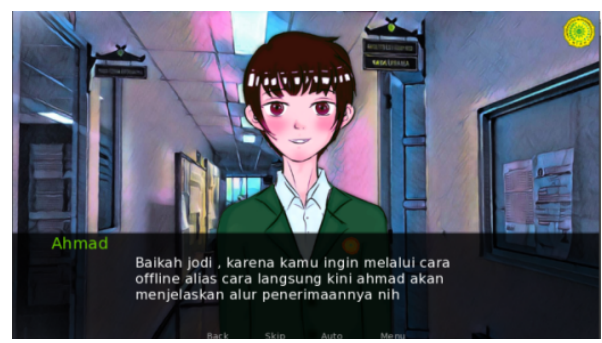

Gambar 3.17 Tampilan informasi "alur offline $^{\prime \prime}$

\subsection{Hasil Pengujian blackbox}

Pengujian aplikasi merupakan tahap terakhir dalam pembangunan perangkat lunak. Pada tahap ini, visual novel ini akan diuji coba baik itu dari segi logika dan fungsi-fungsi supaya layak untuk diimplementasikan. Pengujian ini menggunakan teknik Black Box, yaitu pengujian terhadap aplikasi yang dibangun apakah semua berjalan dengan baik atau tidak dan berfokus pada persyaratan fungsional perangkat lunak yang dibuat.

Pengujian black box menitik beratkan pada fungsi aplikasi. Metode ini digunakan untuk mengetahui apakah perangkat lunak berfungsi dengan benar dan sesuai dengan yang diharapkan.

Pengujian dilakukan terhadap fungsional sistem dan antarmuka. Berdasarkan data hasil kuisioner yang telah dilakukan tersebut dibuat presentase untuk membuktikan bahwa tampilan antarmuka sistem tersebut mudah digunakan oleh pengguna dengan rumus berikut:

Hasil pengujian fungsional game yang telah dihitung persentasenya pada responden menunjukkan bahwa $100 \%$ menyatakan ya setuju dan menyatakan $0 \%$ tidak setuju, dapat disimpulkan dari hasil semua responden bahwa game yang dibuat berfungsi sebagaimana mestinya.

Hasil pengujian usabilitas game hasil pengujian antarmuka diperoleh kesimpulan bahwa hampir seluruh koresponden puas dengan game yang dibuat. Data hasil pengujian menunjukkan bahwa responden sangat setuju $83 \%$, setuju $15 \%$, netral $2 \%$, tidak setuju $0 \%$, dan menyatakan sangat tidak setuju $0 \%$.

Berdasarkan hasil pengujian tersebut, dapat disimpulkan bahwa Game Visual Novel PMB FASILKOM UMRI yang telah dibuat layak untuk dimainkan atau digunakan.

\section{Kesimpulan}

Dari analisa dan pembahasan yang penulis lakukan pada bab-bab sebelumnya, maka dapat diambil kesimpulan sebagai berikut :

1. Visual novel PMB FASILKOM UMRI mampu memberikan informasi mengenai Fasilkom dan juga dapat memberikan evaluasi mandiri kepada user

2. Visual novel PMB FASILKOM UMRI ini terdapat logika fuzzy didalam opsi pilihan atau responnya. Pilihan atau respon yang dipilih memiliki pengaruh dan hasil akhir yang berbeda tergantung dari pilihan yang diambil. 


\section{Daftar Pustaka}

[1] Adrie Satrio, A. G. (2017). Pengembangan Visual Novel Game Mata Pelajaran Ilmu Pengetahuan Sosial diSeekolah Menengah Pertama. 4(1), 1-12. Retrieved from http://journal.uny.ac.id/index.php/jitp

[2] Anggraini, D., \& Putra, N. W. (2017). Aplikasi Logika FUZZY Dalam Teori Permainan Untuk Menentuakan Strategi Pemasaran ( Studi Kasus: Persaingan Alfamart dan Indomaret ). Seminar Nasional Matematika Dan Pendidikan Matematika 2017, 81-87.

[3] Arieska, P. K., Herdiani, N., Sampling, S., \& Relatif, E. (2018). Pemilihan Teknik Sampling berdasarkan Perhitungan Efisiensi Relatif. 6(2).

[4] Chandra, V. A., Intan, R., Purba, K. R., Studi, P., Informatika, T., Industri, F. T., ... Surabaya, J. S. (2018). Perbandingan Performa Turn-Based Game Menggunakan Algoritma Genetika dan Logika Fuzzy. vol $6(2)$. Retrieved from http://publication.petra.ac.id/index.php/tekni k-informatika/article/view/7509

[5] Gunawan, A., Intan, R., Purba, K. R., Studi, P., Informatika, T., Industri, F. T., ... Siwalankerto, J. (n.d.). Penerapan Adaptive Neuro Fuzzy Inference System pada Real Time Strategy Battle Arena Game.

[6] Hormansyah, D. S., Retno, A., Hayati, T., Pribadi, D. T., Studi, P., Informatika, T., ... Pustaka, K. (2018). Implementasi FSM (Finite State MAchine) pada Game Perjuangan Pangeran Diponegoro. 4(4), 290-297.

[7] Imam Adli, HarunMukhtar, J. A. A. (2018). Perancangan dan pembuatan visual novel sejarah kh. ahmad dahlan sebagai media pembelajaran berbasis android. RABIT (Jurnal Teknologi Dan Sistem Informasi Univrab), 3(2), 69-82.

[8] Insani, H., Supraptono, E., Hakim, L., Boedi, S. M. P., \& Cilacap, O. (2016). Penerapan Model CTL Berbantuan Media Visual Novel dalam Mengidentifikasi Kegunaan Program Aplikasi. 1(2), 8-12.

[9] Insanittaqwa, V. F., Kuswardayan, I., \& Sunaryono, D. (2014). Game Edukasi ‘ Simulasi Haji' Menggunakan Ren ' Py pada Perangkat Android untuk Simulasi Perjalanan Ibadah Haji. 3(1).

[10] Kusuma, M. R., Djamil, H., Bastian, I., \& Rosadi, A. (2017). Pembuatan Visual Novel dengan Tujuan Edukasi Berbasis Android.

[11] Marzian, F., \& Qamal, M. (2017). Game RPG “ THE ROYAL SWORD " berbasis Desktop dengan menggunakan metode Finite State Machine ( FSM ). Jurnal Sistem Informasi, 1(2), 61-96. Retrieved from https://ojs.unimal.ac.id/index.php/sisfo/articl e/view/244

[12] Murtikah, D. (2016). Inggris dasar berbentuk Visual Novel menggunakan Unity 3D. 6(1), 1-10.

[13] Prasetya, I. A., \& Safriadi, N. (2015). Penerapan Visual Novel Dari Cerita Rakyat Asal Usul Kota Pontianak. 1(1), 1-5.

[14] Rahadian, M. F., Suyatno, A., \& Maharani, S. (2016). Penerapan Metode Finite State MAchine pada game " THE RELATIONSHIP ." Jurnal Informatika Mulawarman, 11(1), 14-22.

[15] Ratanajaya, D., \& Wibawa, H. A. (2018). Implementasi Kecerdasan Buatan dalam Menentukan Aksi Karakter pada Game RPG dengan Logika Fuzzy Tsukamoto. Khazanah Informatika: Jurnal Ilmu Komputer Dan Informatika, $4(2), \quad 82$. https://doi.org/10.23917/khif.v4i2.6744

[16] Risma Shafriyani, Hasanuddin, F. A. W. (2019). Penerapan metode Fonik untuk Game Edukasi Penyandang Disleksia Menggunakan Visual Novel. 9(2), 358-368.

[17] Saputra, S. A., Haryanto, H., \& Dolphina, E. (2019). Skenario Dinamis Menggunakan Finite State Machine pada Game Pengenalan Tempat dan Peristiwa Bersejarah. EKSPLORA INFORMATIKA, $8(2)$, $112-121$. https://doi.org/10.30864/eksplora.v8i2.155

[18] Setiawan, A., \& Pengaraian, U. P. (2018). Logika Fuzzy Dengan M A T L A B ( Contoh Kasus Penelitian Penyakit Bayi dengan Fuzzy Tsukamoto ).

[19] Tommy, L., Isnanto, B., \& Rian, R. (2015). Prototipe Game Cerita si Budi. 2(1), 1-11.

[20] Tim Penyusun Umri. (2019). Buku Panduan Akademik Fasilkom Umri tahun ajaran 2019/2020. Pekanbaru: Umri 